\title{
INGENIO Y MUJER EN EL DISCURSO HEGEMÓNICO Y HETERÓNOMO DE LA TEMPRANA MODERNIDAD ESPAÑOLA
}

\author{
René Aldo Vijarra \\ (Universidad Nacional de Córdoba, Argentina) \\ renevijarra@hotmail.com
}

\begin{abstract}
RESUMEN: Durante el siglo XVI, una serie de dispositivos discursivos hegemónicos construyeron una representación de los sujetos y esos discursos tuvieron una amplia difusión e influencia en la centuria siguiente. El Examen de ingenios para las ciencias (1575) de Juan Huarte de San Juan fue uno de esos discursos performativos que delimitó las competencias y funciones de los hombres teniendo en cuenta el ingenio de cada quien. Si bien la mujer no fue el tema del tratado, no estuvo ausente de la mirada del médico navarro, quien ofreció su propia perspectiva. Por otro lado, y en franca disidencia con estas opiniones, dos mujeres, María de Zayas y Mariana de Carvajal, desde el campo literario y con una posición excéntrica, manifestaron en diferentes obras su resistencia a esos principios biológicos y universales a través de la voz de las enunciadoras de los paratextos y de la voz y accionar de los personajes.
\end{abstract}

PALABRAS ClAVE: Siglo de Oro, Discurso, Ingenio, Mujer.

\section{WIT AND WOMAN IN THE HEGEMONIC AND HETERONOMIC DISCOURSE OF EARLY MODERN SPAIN}

ABSTRACT: During the XVI century, a series of hegemonic devices created a representation of subjects and those discourses had a widespread dissemination and influence in the following century. Juan Huarte de San Juan's work Examen de ingenios para las ciencias (The Examination of Men's Wits, 1575/1594) was one of those performative discourses that delimited the abilities and functions of men taking into account the wit of each. Even though woman was not the subject of the text, she was not absent from the eye of the Navarrese doctor, who offered his own perspective. On the other hand - and in honest disagreement with those opinions - , two women, María de Zayas and Mariana de Caravajal, from the field of literature and with an ex-centric position, expressed in different works their resistance to those biological and universal principals through the voice of speakers in the paratexts and the voice and action of characters.

KEYWORDS: Spanish Golden Age, Discourse, Wit, Woman.

\section{DISCURSO, PERFORMATIVIDAD E IDENTIDAD}

Todo discurso es producto de una práctica enmarcada histórica y socialmente y en él se inscribe un modo de concebir la vida y el mundo. Angenot (2010: 32) señala que algunos discursos tienen una potencia con la cual se imponen, otros en cambio son «murmullos periféricos de los grupúsculos disidentes»; sin embargo, es en el primero, en el discurso 
Ingenio y mujer en el discurso hegemónico y heterónomo de la temprana modernidad española

social, ${ }^{1}$ donde se encuentra la hegemonía de lo pensable y decible. El pensador entiende la hegemonía «como un instrumento de control social, como una vasta sinergia de poderes, restricciones y medios de exclusión ligados a arbitrarios formales y temáticos» (Angenot, 2010: 32). Y esa hegemonía es la que impone y legitima ciertos pensamientos como grandes pensamientos y a ciertos intelectuales como la encarnación de una época, lo que produce la dominancia de ciertos hechos semióticos que determinan lo enunciable y privan de medios de enunciación a lo impensable. Todo lo que escapa a la lógica hegemónica del discurso social, Angenot lo denomina «heteronomía».

Según nuestra perspectiva, esos murmullos periféricos y heterónomos que se apartan de lo enunciable permitido lo hacen desde una posición excéntrica. Al decir excéntrica nos remitimos a la postura de De Lauretis, quien señala que todo desplazamiento de lo seguro a lo desconocido implica una transformación, una des-identificación de un grupo, de una familia, de una casa. Este desplazamiento, que implica dejar o renunciar a un lugar seguro, ya sea social, geográfico, afectivo, etc. es, además, «un des-plazamiento del propio modo de pensar: comporta nuevos saberes y nuevas modalidades de conocimiento» (De Lauretis, 2000: 139). La posición de un sujeto excéntrico entra en tensión con los dispositivos del aparato institucional y los cuestiona, luego de tomar conciencia de las desigualdades sustentadas por ellos, en otras palabras, «esos murmullos periféricos de grupúsculos disidentes se organizan siempre como resistencia» (Angenot, 2010: 52).

En la temprana modernidad española, una serie de discursos provenientes de los estamentos de poder llevó a cabo una acción modeladora sobre sus habitantes y tuvo por finalidad una política normativa y performativa, cuya estrategia consistió en presentar como naturales los atributos, las funciones y las condiciones morales de los sujetos. Ese proceso de subjetivación se realizó paulatinamente por medio de discursos hegemónicos, como Examen de ingenios para las ciencias (1575) de Juan Huarte de San Juan, que puso el foco de atención en el proceso de subjetivación de los hombres en beneficio de la república. Por otro lado, desde una perspectiva excéntrica, la práctica discursiva de María de Zayas y Mariana de Carvajal ofrece resistencia a la performatividad del discurso hegemónico basada en el determinismo biológico.

La performatividad debe entenderse como una práctica reiterativa y referencial de interpelación y reprimenda mediante la cual el discurso produce los efectos que nombra, regula e impone, y «si el poder que tiene el discurso para producir aquello que nombra está asociado a la cuestión de la performatividad, luego la performatividad es una esfera en la que el poder actúa como discurso» (Butler, 2002: 316). La fuerza normativa de la performatividad condiciona la identidad del sujeto, la que está determinada por el momento histórico y por ámbitos institucionales particulares.

La identidad surge en el interior de formaciones y prácticas discursivas mediante estrategias enunciativas específicas; además, emerge en un juego de modalidades de poder y solo puede construirse en la relación con los otros. Hall (2011) sostiene que las identidades son el constructo discursivo, la narración de la articulación de las

\footnotetext{
${ }^{1}$ Para Angenot (2010: 21) más allá de los lenguajes, de la variedad de las prácticas significantes, de los estilos y de las opiniones se puede reconocer las dominancias interdiscursivas, y es por esto que prefiere utilizar el concepto discurso social en singular y lo define como «todo lo que se dice y se escribe en un momento de la sociedad; todo lo que se imprime [...] Todo lo que se narra y argumenta».

2 «Uso "identidad" para referirme al punto de encuentro, el punto de sutura entre, por un lado, los
} 
interpelaciones recibidas con la adhesión temporaria e individual a ciertas posiciones que el sujeto ha ido ocupando. ${ }^{2}$ Para Grossberg (2011: 168), «el sujeto describe una posición dentro de un campo de subjetividad o un campo fenomenológico, producido por una máquina subjetivante específica»; desde esta perspectiva, podemos entender por «máquina subjetivante específica» al proyecto/programa político, social y cultural per-formador de subjetividades, que a la vez que propone el cumplimiento de la norma, ofrece reconocimiento a quienes lo acatan, y sanciona a los que desobedecen. Los ejes programáticos del proyecto intentan per-formar y disciplinar sujetos, quienes al aceptar la interpelación adoptan una posición subjetiva que los convierte en sujetos con identidad.

\section{DISPOSITIVOS DISCURSIVOS}

Foucault sostiene que a lo largo del siglo XVII hubo toda una invención de las formas de poder a las que denomina tecnología política, cuyos mecanismos controlaron cosas y personas. El pensador francés llama tecnología individualizante de poder a aquella que enfoca a los individuos hasta en sus cuerpos y en sus comportamientos: «se trata, grosso modo, de una especie de anátomo-política, una política que hace blanco en los individuos hasta anatomizarlos», y a partir del siglo XVIII, la tecnología pone el blanco en la población: «por lo tanto, creo yo hay dos grandes revoluciones en la tecnología del poder: el descubrimiento de la disciplina y el descubrimiento de la regulación, perfeccionamiento de una anátomo-política y perfeccionamiento de una bio-política» (Foucault, 1991: 18-19).

Si bien Foucault propone una fecha más tardía, podemos decir que en España, ya en el siglo XVI, una tecnología del sujeto afloró en una red de dispositivos cuyo fin era disciplinar a hombres y mujeres, tanto en el modo de conducirse en la vida social como en el cuidado de su vida interior. Tratados filosóficos y morales y manuales de conducta sobre las actitudes y aptitudes esperadas en la vida pública y privada estuvieron a la orden del día y cumplían la función de formar varones y mujeres a lo largo de su existencia social. En ese marco de control, el poder disciplinador del aparato institucional produjo, legitimó e impuso una serie de discursos como dispositivos disciplinarios que construyeron una representación de los sujetos que, también, sirvieron para performarlos de acuerdo a unos intereses determinados.

Según García Fanlo (2011: 1), hay que pensar una relación estrecha entre el sujeto y los dispositivos en la medida en que inscriben en el cuerpo un conjunto de praxis, saberes, instituciones, «cuyo objetivo consiste en administrar, gobernar, controlar, orientar, dar un sentido que se supone útil a los comportamientos, gestos y pensamientos de los individuos». Un dispositivo es un régimen social productor de subjetividad, es decir, productor de sujetos-sujetados a un orden del saber/poder cuya estructura sostiene un régimen de verdad, y cada dispositivo porta una especificidad en cuanto al tipo de sujeto que pretende performar (García Fanlo, 2011). Los dispositivos disciplinarios propios de

2 «Uso "identidad” para referirme al punto de encuentro, el punto de sutura entre, por un lado, los discursos y prácticas que intentan interpelarnos, hablarnos o ponernos en nuestro lugar como sujetos sociales de discurso particulares y, por otro, los procesos que producen subjetividades, que nos construyen como sujetos susceptibles de "decirse". De tal modo, las identidades son puntos de adhesión temporaria a las posiciones subjetivas que nos construyen las prácticas discursivas» (Hall, 2011: 20). 
Ingenio y mujer en el discurso hegemónico y heterónomo de la temprana modernidad española

cada institución interpelan al sujeto transformándolo en sujeto normativizado de acuerdo a determinados atributos y funciones que son útiles y necesarios para determinados fines.

\section{EXAMEN DE INGENIOS, UN DISCURSO HEGEMÓNICO}

Examen de ingenios para las ciencias constituyó el primer intento de análisis científico de la inteligencia del hombre. El sujeto social Juan Huarte de San Juan operativiza el tópico del ingenio para demostrar las «muchas diferencias de ingenio que hay en la especie humana» (1946: 40) y poder performar tipos de hombres de acuerdo a su naturaleza e ingenio. De este modo se propone ejercer sobre los sujetos masculinos un control que impidiera a los incompetentes ocupar posiciones para las cuales no estaban habilitados y, para cumplir su cometido, Huarte de San Juan conformó una definición de ingenio y delimitó sus atributos y funciones desde el campo de la filosofía natural, donde él mismo se autoinscribió más allá de su profesión de médico.

El ingenio es sinónimo de inteligencia, y Huarte lo caracteriza como fecundidad de la mente o capacidad de engendrar conceptos o figuras representativas de la naturaleza de las cosas. Para García-García (2003: 6), «representación es la palabra más adecuada para caracterizar el ingenio como conjunto de las capacidades humanas de representación —imaginación, entendimiento y memoria —. Tales capacidades son las que generarán las artes y las ciencias».

Si bien la mujer no es tema central del tratado, ella no está exenta de ser objeto de análisis, y como dice Laqueur (1994: 201): «en los mismos textos en que se excluye a las mujeres y se les niega la existencia y la subjetividad propias, participan como sujetos. Allí están, en el mismo lugar que las declara ausentes». El tratado huarteano se inserta en una larga tradición misógina en donde el enunciador sustenta su postura sobre la inferioridad intelectual de la mujer basándose en las divinas Escrituras y, de ese modo, adhiere a la cosmogonía cristiana sobre la creación:

Llenándolos Dios a ambos de sabiduría, es conclusión averiguada que le cupo menos a Eva, por la cual razón dicen los teólogos que se atrevió el demonio a engañarla y no osó tentar al varón temiendo su mucha sabiduría. La razón de esto es, como adelante probaremos, que la compostura natural que la mujer tiene en el celebro no es capaz de mucho ingenio ni de mucha sabiduría (Huarte de San Juan, 1946: 42).

El enunciador utiliza primero un fundamento teológico basado en las Sagradas Escrituras - Génesis 2, Eclesiástico 17- como estrategia para enlazar su materia de estudio con la tradición cristiana $\mathrm{y}$, de este modo, lograr la adhesión, en lo posible incuestionable, de los examinadores de la obra, primero, y de sus lectores, después. A continuación, como corresponde a un enunciador con un saber específico, anticipa una explicación científica para justificar la desigualdad de origen divino; es decir, prioriza la interpretación racional a la argumentación basada en la fe en el dogma, ya que los hombres de ingenio son «los que no se contentan hasta saber la causa particular del efecto» (Huarte de San Juan, 1946: 99):

Luego la razón de tener la primera mujer no tanto ingenio le nació de haberla hecho Dios fría y húmida, que es el temperamento necesario para ser fecunda y paridera, y el que 
contradice al saber; y si la sacara templada como Adán, fuera sapientísima, pero no pudiera parir ni venirle la regla si no fuera por vía sobrenatural (Huarte de San Juan, 1946: 614).

Por lo tanto, desde el principio de los tiempos, a la mujer le queda vedada la posibilidad de alcanzar el conocimiento por mandamiento divino, por un lado, y por otro, debido a causas naturales, la frialdad y humedad. Dos fundamentos de peso que sirven para justificar su condición de inferioridad y la consecuente exclusión de la condición de sujeto pleno con todo lo que esto implica: exclusión del espacio público y el enclaustramiento en el espacio doméstico o conventual. De este modo, el hombre se construirá como el sujeto perfecto y medida de todas las cosas por su exceso de calor, que es el instrumento primario de la naturaleza, y, teniendo en cuenta la conexión biológica testículo-cerebro, el varón es un sujeto pleno en su condición natural de caliente y seco, lo que implica la potencialidad de procrear hijos y conceptos; en cambio, la mujer es incompleta en tanto que solo puede concebir hijos por su condición de fría y húmeda.

Con estos fundamentos biológicos, el enunciador sustenta la desigualdad sexogenérica y, además, respaldado con fundamentos teológicos, afirma que en tanto que a la primera mujer le cupo menos saber, las descendientes de Eva corren la misma suerte. Desde esta representación de mujer, la inferioridad biológica conlleva una inferioridad intelectual que acarrea la imperfección moral. Todo ello es utilizado por el saber/poder patriarcal para justificar la imperfección femenina y la consecuente sujeción al hombre, ya sea el padre, el hermano o el marido. Como dice Berriot-Salvadore (1993: 119): «El discurso científico es tributario de un orden del mundo que conviene legitimar, mostrando que el papel de cada uno de los sexos se inscribe en la naturaleza».

La re-presentación de mujer se construye con el atributo de la fecundidad y la potencialidad para parir, pero conlleva la carencia de ingenio y la consecuente imposibilidad de acceder al conocimiento:

Pero, quedando la mujer en su disposición natural, todo género de letras y sabiduría es repugnante a su ingenio. Por donde la Iglesia católica con gran razón tiene prohibido que ninguna mujer pueda predicar ni confesar ni enseñar; porque su sexo no admite prudencia ni disciplina (Huarte de San Juan, 2005: 615).

El lexema mujer se completa aquí con dos semas cardinales con valores negativos: el primero, «imprudencia», lo que implica poca consideración a su condición de sujeto, en tanto que prudente es únicamente el hombre sabio y mesurado, ambos atributos negados a la mujer por sus debilidad natural. El segundo, «indisciplina», en la medida que no es capaz de incorporar un saber y, en su referencia contextual, tampoco es disciplinable, es decir, «apta ni dócil para ser enseñada» (Covarrubias, 1995: 426); y como consecuencia de no ser disciplinada fue tentada por el demonio. Según Huarte de San Juan, esto tiene su explicación en la falta de calor necesario, ya que su condición primordial de la mujer es el exceso de frialdad y humidad. 
Ingenio y mujer en el discurso hegemónico y heterónomo de la temprana modernidad española

LOS «MURMULLOS PERIFÉRICOS»

La sujeto social María de Zayas desea posicionarse en el campo cultural dominado por el poder hegemónico masculino y se propone hacerlo no solo como mujer, sino también como mujer con un saber-hacer en el campo literario y en franca disidencia con quienes pretenden sujetarla y sujetar a todas las mujeres a determinismos biológicos $\mathrm{y}$, de ese modo, limitar sus capacidades.

En el prólogo a las Novelas amorosas y ejemplares (1637), la sujeto de enunciación transciende la mera presentación de la obra para intentar construirse como sujeto pleno señalando que da sus borrones a la imprenta, «donde se averigua la pureza de los ingenios» (Zayas, 2010: 159); por lo tanto, da por descontado que es ingeniosa y, luego, se atreve a plantear la igualdad entre el hombre y la mujer con argumentos provenientes de la ciencia médica (sangre y órganos). Y si esto ya es un atrevimiento, la osadía va más lejos cuando sostiene que no solo son aptas, sino quizás hasta más agudas y para esto se remite a la teoría de Huarte de San Juan (1946: 174), quien afirma que «de la humedad, es dificultoso saber qué diferencia de ingenio pueda nacer, pues tanto contradice la facultad racional», en cambio, la enunciadora sostiene lo contrario: «por ser [la mujer] de natural más frío, por consistir en humedad el entendimiento» (Zayas, 2010: 160). Paradójica y fina ironía, ya que, por un lado, retoma la teoría huarteana cuando descree del determinismo biológico que el agente pretende demostrar $\mathrm{y}$, por otro lado, evidencia conocimientos científicofilosóficos que rebate planteando lo contrario.

$\mathrm{Su}$ posicionamiento ideológico se sustenta en la igualdad e, incluso, superioridad intelectual de las mujeres, hecho que la induce a otorgarles las cualidades de agudeza e ingenio, reservadas solo para el varón según el discurso hegemónico. Por lo tanto, la enunciadora, al otorgar esos atributos a las mujeres, se está desplazando de la norma y construyendo una representación de mujer como sujeto pleno, esto es, sujeto con ingenio; y, de este modo, disiente con el discurso hegemónico. Además, su propia ingeniosidad le señala que la identidad de género es una construcción sociocultural que no se corresponde con fundamentos naturales: «Porque si en nuestra crianza, como nos ponen el cambray en las almohadillas y los dibujos en el bastidor, nos dieran libros y preceptores, fuéramos tan aptas para los puestos y para las cátedras como los hombres». La enunciadora tiene una clara conciencia de que la identidad de las mujeres está condicionada por el poder masculino, al que califica con términos referidos a lo humano y a lo político: «Esto no tiene, a mi parecer, más respuesta que su impiedad o tiranía en encerrarnos y no darnos maestros» (Zayas, 2010: 160, 159).

El texto zayesco va acompañado de un segundo paratexto, «Prólogo de un desapasionado», que declara: «La señora doña María de Zayas, gloria de Manzanares, y honra de nuestra España [...] por prueba de su pluma da a la estampa estos diez partos de su fecundo ingenio, con nombre de Novelas» (Zayas, 2010: 163).

El/la enunciador/a retoma el determinismo biológico de Huarte de San Juan, para quien la concepción biológica e intelectual están estrechamente vinculadas en tanto que los testículos informan el temperamento al cerebro, y el entendimiento como potencia generativa produce hijos: «Y si nos acordamos que la frialdad y humidad son las calidades que echan a perder la parte racional, y sus contrarios, calor y sequedad, la perfeccionan y aumentan» (Huarte de San Juan, 2005: 613), lo que permite la generación de hijos/conceptos. 
En el segundo prólogo, también se ha invertido la proposición huarteana, ya que el útero y los testículos femeninos, que son fríos y húmedos, han informado al cerebro para gestar y parir diez hijos/libros. Con esto queda confirmado lo señalado por la enunciadora del primer prólogo: «por ser de natural más frío por consistir en humedad el entendimiento» (Zayas, 2010: 160).

No menos ingeniosa es la voz de la enunciadora del paratexto de Navidades de Madrid y noches entretenidas, en ocho novelas (1663) de Mariana de Carvajal (1993: 5): «Atento y curioso lector, aunque no me será posible el conseguir lucidos desempeños en el arresto de tan conocido atrevimiento, no por eso dejaré de servirte con los sucesos que en este pequeño libro te ofrezco, aborto inútil de mi corto ingenio».

En un rapto de falsa modestia, la ingeniosa enunciadora previene al futuro receptor sobre la imposibilidad de lograr una buena producción, que le permita lucirse en el oficio de la escritura, aunque esto no la amedrenta para persistir en sus propósitos. Y si en Zayas la «inclinación» es el impulso movilizador que la induce a practicar la escritura, no menos potente es el «arresto», es decir, la determinación en el atrevimiento de llevar adelante un «desempeño» para el cual ellas no estaban plenamente habilitadas. La osadía de la enunciadora se destaca más aún dado que hace un uso consciente del término «atrevimiento» para anunciarle su desobediencia y, de este modo, se posiciona en un lugar excéntrico a la norma y demostrando que es capaz de desempeñarse como escritora. Finalmente, completa el ofrecimiento haciendo referencia a su obra como «aborto inútil de mi corto ingenio».

Similar a la humildad de la enunciadora de la obra de Zayas es la docilidad de la voz enunciadora del texto de Carvajal. Docilidad que acaba por hacerse poco confiable, ya que brinda algo de escaso valor, sin embargo, lo ofrece; por otra parte, recurre a un término de la ciencia médica, aborto, y lo enlaza con el ingenio y, nuevamente, aparece la concepción biológica-intelectual la obra huarteana.

El ingenio «desciende de uno de estos tres verbos latinos: gigno, ingigno, ingenero» (Huarte de San Juan, 1946: 60). Gigno significa «engendrar, dar a luz, nacer»; ingigno: «hacer nacer en, fecundar, inculcar»; e ingenero: «engendrar, infundir, inspirar, crear, producir, dar a luz». El sema nuclear en los tres lexemas es la procreación (engendrar) y los semas contextuales de ingenio remiten al ciclo de reproducción humana y a la creación de conceptos. Laqueur (1994) señala que la generación de las cosas en la naturaleza y en el arte tienen lugar de la misma forma: el cerebro es el instrumento de la concepción en la producción del arte porque es el instrumento del alma, del mismo modo en que el útero es el cerebro o instrumento de la concepción en la naturaleza. A esta altura, ambas escritoras están señalando que como sujetos plenos tienen la capacidad no solo de concebir hijos, sino también, libros.

Para reforzar la proclamada modestia, la enunciadora pone en evidencia su «corto ingenio», es decir, su carencia de inventiva y capacidad para la escritura, por lo tanto, solo puede ofrecer un aborto, entonces pide disculpas de antemano «por los defectos de una tan mal cortada pluma» (Carvajal, 1993: 5). Más allá del aborto de su corto ingenio, nada la detiene para escribir y publicar su obra; y, finalmente, la aparente humildad es tal que no la «desvanecerán los plausos» ni la ofenderá «la censura»y, estratégicamente, hace uso de una fórmula de ofrecimiento: «pues mi mayor vencimiento será el estar a tus plantas siempre, atenta a tan prudente corrección» (Carvajal, 1993: 5). Al dejar sentado tal ofrecimiento le hace creer que, a pesar de su atrevimiento e imprudencia al tomar la pluma, 
sigue subordinada a la apreciación del «atento y curioso lector» $\mathrm{y}$ «todo esto es justificado con delicadeza, humildad, docilidad y sumisión y con ello fácilmente consiguen embaucar a todos cuantos tropiezan con sus obras» (Sánchez Dueñas, 2008: 300).

La conciencia del desplazamiento de la norma es tenida como atrevimiento de quien no es prudente e incursiona en el campo de las letras. La escritura, en general, y la ficción, en particular, eran un ámbito exclusivamente masculino, por lo tanto, son consideradas atrevidas —excéntricas en términos de De Lauretis - las que transgreden, desobedecen y quebrantan la virtud del silencio inherente a su condición femenina.

\section{ENGAÑOS, MAÑA E INGENIO}

En muchas de las maravillas relatadas en las Novelas amorosas y ejemplares de Zayas existen ingeniosos personajes femeninos que ponen en jaque la masculinidad. Tal es el caso de don Fadrique, «El prevenido engañado», donde el protagonista es burlado en reiteradas oportunidades por un grupo de mujeres que lo colocan en una situación deshonrosa e incluso contradictoria con sus propios principios.

La primera, Serafina, acepta la propuesta matrimonial de don Fadrique, pero retrasa la boda varios meses por problemas de salud, que no es otro que el embarazo de su anterior pretendiente. El alumbramiento se produce, la criatura es abandonada y don Fadrique, que ha sido testigo del hecho, toma bajo su responsabilidad a Gracia, la recién nacida, y, dejándola al cuidado de una tía, le ordena que a los tres años la ingrese a un convento. Serafina, la madre, cuyo nombre evoca a los espíritus bienaventurados, nada tiene de angelical, ya que posee la astucia para engañar a sus padres, a su prometido e incluso a la sociedad toda, que la tiene por santa al haber ingresado a un monasterio ocultando el abandono de una hija.

El segundo amor es una viuda, Beatriz, de quien logra la aceptación con la condición de esperar el tercer año del duelo. Es Beatriz, como su nombre lo indica, portadora de belleza angelical, pero detrás de esta fachada se esconden sus viciosos apetitos, que no son otros que las atenciones amorosas ofrecidas al feo y abominable sirviente negro.

En Madrid, la fortuna le sigue adversa al protagonista debido a que «todas saben amar y engañar, y así me tienen tan escarmentado las discretas que deseo tener batalla con una boba». Conoce a la tercera, doña Violante, con un «entendimiento tal que en letras humanas no hay quien la aventaje» (Zayas, 2010: 317). Ella acepta los favores amorosos hasta que viola el acuerdo y lo engaña con «mozuelo de tan pocos años».

En las afueras de Barcelona conoce a la cuarta mujer, una duquesa, que lo invita a comer y hacer la siesta con ella, y así pasaron la tarde hasta que al anochecer llega el duque y la dama debe esconder al ocasional amante. Para salir de tan intrincada situación la astuta duquesa burla a su marido con la verdad al relatar un cuento con los hechos sucedidos esa tarde. Nuevamente es una mujer la que manipula con ingenio la situación, deshonrando a un marido y seduciendo a un hombre.

Ya de regreso a su lugar de origen decide visitar a Gracia, la hija de su primer amor, y al fin «de su plática y descuido conoció don Fadrique haber hallado el mismo sujeto que buscaba», mujer hermosa pero boba. Se casa con ella y pone a prueba su ignorancia enseñándole que la vida de casada era velar por la noche el sueño del marido, hasta que un caballero galán y astuto se aprovecha de la simplicidad de Gracia y la seduce. Le acontece a 
don Fadrique lo mismo que al duque con la duquesa con la diferencia que el deshonrado es él, y que la discreta duquesa engañó con la verdad a su marido, y aquí la verdad de Gracia lo desengaña de su primer pensamiento: «Bien digo yo que las mujeres el saber las hace que se pierdan» (Zayas, 2010: 333-334).

Don Fadrique sostiene que «una mujer no había de saber más de hacer su labor y rezar, gobernar su casa y criar sus hijos; y lo demás eran bachillerías y sutilezas que no servían sino de perderse más presto» (Zayas, 2010: 301), situación que se contrapone con la mayoría de los personajes femeninos de la obra; por ejemplo, en «La Burlada Aminta y venganza del honor», la narradora dice de su protagonista: «Mostró sus gracias, como era leer, escribir, y contar, y otras muchas» (Zayas, 2010: 240). Otro tanto ocurre en «El juez de su causa» con Estela, quien logra por sus propios méritos, pero con disfraz de varón, el cargo de virrey de Valencia y debe juzgar a su propio enamorado, a quien hace confesar su amor con ingeniosas estrategias. También muy ingeniosa es su contrincante Claudia, que travestida en Claudio logra engañar a todos, y «todo lo que se hace con maña», dice el prólogo, «aunque no sea virtud, es ingenio» (Zayas, 2010: 160).

Igual que a don Fadrique le ocurre a don Marcos, de «El castigo de la miseria». El protagonista se casa con doña Isidora, que «no había sido casada, si bien estaba en opinión de viuda, mujer de buen gusto y de alguna edad, aunque la encubría con las galas, adornos e industria [...] y muy rica según decían» (Zayas, 2010: 256). Finalmente, la mañana siguiente a «la noche de la posesión» dio principio a los desengaños de don Marcos: la belleza y juventud eran un artificio de doña Isidora, «que a la cuenta estaban más cerca de cincuenta y cinco que de treinta y seis» (Zayas, 2010: 276); Agustinico, el sobrino, no era tal, sino su amancebado; la propiedad no era tan propia, sino rentada, y la dote no existía. El ingenio femenino ha hecho ver a don Marcos lo que no existe, lo ha deshonrado, lo ha empobrecido.

No menos ingeniosas son los personajes femeninos de Navidades de Madrid y noches entretenidas, en ocho novelas de Mariana de Carvajal. Tal es el caso de la protagonista de «La Venus de Ferrara»: Floripa, viuda de Astolfo, duque de Ferrara, después de la muerte de su marido debe tomar a su cargo la elección del consorte para su hija Venus; sin embargo, la madre no le impone un pretendiente y prioriza los propios deseos de la doncella, «advirtiéndoles que había de ser el escogido aquel a quien ella se inclinara» (Carvajal, 1993: 32).

A la hora de elegir esposo y en el juego de ver y ser vista, madre e hija traman un ardid para la selección del futuro consorte que pone a prueba el verdadero interés de los cinco pretendientes, quienes deben competir en bizarría, elocuencia y belleza, todos atributos de una masculinidad plena. Los futuros consortes pondrán en juego todas sus habilidades poéticas, su destreza en el campo taurino y su gallardía física ante el tribunal femenino encargado de elegir a quien se alzará con el máximo galardón, el sí de la pretendida. A pesar de todas sus habilidades físicas y facultades racionales, ellos serán engañados por la ingeniosidad de la futura esposa, quien se hace pasar por una dama de la corte, Eufrasia, y esta fingirá ser Venus. Cuatro pretendientes intentan conquistar a Eufrasia en el rol de Venus, y solo uno, Alfredo, pone los ojos en la verdadera Venus y obtiene el consentimiento de la doncella. Finalmente, todos «quedaron corridos de que se conociera su codicia, y admirados de la discreción de Venus» (Carvajal, 1993: 41).

La historia de Venus replica la de su madre, quien en su juventud, vestida de pastora, se atrevió a entrar a palacio y conocer a quien sería su esposo. La narradora 
Ingenio y mujer en el discurso hegemónico y heterónomo de la temprana modernidad española

describe a Floripa como «diestra en la música y aguda de entendimiento» y que se «preciaba de escribir algunos versos». Esta mujer de agudo entendimiento le permitirá a su hija estar encubierta y es consciente de que la verdadera felicidad está en la propia voluntad: «como Venus viva contenta, la mayor riqueza es el gusto» (Carvajal, 1993: 28, $33)$.

Igual que el caso anterior, en «El amante venturoso» se pone de manifiesto la libre voluntad de la doncella en la elección del marido. En este caso, Carlos Milanés se enamora de Teodora, quien le corresponde; sin embargo, ella se las ingenia para hacerle creer a su padre «que no tenía más voluntad que la suya». Entonces simula mostrarse esquiva ante las propuestas matrimoniales, y, frente a la sugerencia de Carlos, el padre responde: «No sé qué responda — dijo Octavio — , porque se muestra tan rebelde en tratándola de casamiento que, derramando lágrimas, me ha obligado a cerrar la puerta a todos los pretendientes. Quiérola tan tiernamente que no me atrevo a forzar su voluntad» (Carvajal, 1993: 82, 75).

Teodora no se niega al estado marital; lo que en realidad busca es llegar a esa posición con el hombre elegido por ella y, de ese modo, satisfacer su propia voluntad. Cuando el tío de Carlos va a solicitarla, el padre responde: «Pluguiera a Dios, señor Antonio Milanés, fuera yo tan dichoso que Teodora me obedeciera, pues se muestra tan rebelde que no me atrevo a casarla por fuerza». Lo que no sabe el padre es que entre ella y el pretendiente ya tienen concertadas sus voluntades $\mathrm{y}$, cuando finalmente el padre le propone consorte, Teodora finge el recato debido y la narradora dice: «Quedó tan loca la enamorada doncella que, bañando el rostro de encendidos colores, lo atribuyó su padre a su acostumbrada honestidad» (Carvajal, 1993: 82). Finalmente los enamorados se casan.

Otro caso semejante es el de Lisena de «Amar sin saber a quién»: ella es «tan clara y aguda de entendimiento que ponía en admiración a quien la escuchaba» (Carvajal, 1993: 186); en un juego de escuchar sin ser vista, ver sin ser sentida, irá descubriendo con ingenio la identidad del desconocido amante.

Los ejemplos podrían multiplicarse en ambas autoras. La narrativa zayesca, al discrepar con la concepción dominante, se desplaza del modelo imperante de hombre como único sujeto ingenero y medida de todas las cosas y presenta dos personajes masculinos, un avaro y un cornudo, manipulados por la habilidad discursiva, por una sexualidad dominante y la libertad de acción de una serie de personajes femeninos que se imponen y los dejan en ridículo.

Los personajes femeninos de Navidades de Madrid, en general, responden al modelo propuesto y promovido por los discursos hegemónicos de la época con respecto a la belleza, honestidad, usos y costumbres de la vida social. Floripa, por ejemplo, es honesta, recatada y de «hermoso rostro de honestos colores». No le va a la zaga su hija Venus que «era muy hermosa, pues tantos príncipes se determinaban a servirla» (Carvajal, 1993: 25, 32). También, Teodora es poseedora de una singular hermosura, «tan celebrada de todos que la llamaron el milagro del aquel tiempo» (Carvajal, 1993: 74). Lo novedoso se presenta en el ingenio de los personajes femeninos, y según dice Cubillo Paniagua (2002: 10): «Mariana de Carvajal a diferencia de una autora como María de Zayas, no denunciaba en sus textos la subordinación de la mujer ni reclamaba para ella ciertos derechos [...] aunque sus heroínas eran mujeres inteligentes, muchas de ellas con cierto nivel educativo». A esto debemos agregar que casi la totalidad de las protagonistas participan activamente en esa decisión tan trascendental, como es la elección del marido para toda la vida y, por eso, se 
movilizan y ponen en acción algunas estrategias ingeniosas para alcanzar la propia voluntad.

\section{A MODO DE CONCLUSIÓN}

La apropiación del ingenio es un hecho impropio para una mujer del siglo XVII teniendo en cuenta que según los discursos hegemónicos de la época es un atributo exclusivo y excluyente del varón. Algunas mujeres del Siglo de Oro, que intentaron hacer púbica su voz y sus prácticas, tuvieron que enfrentar la misoginia de larga trayectoria y, como dice Gerda Lerner (1990: 319): «la hegemonía masculina en el sistema de símbolos adoptó dos formas: la privación de educación a las mujeres y el monopolio masculino de las definiciones». En otras palabras, el hombre de ingenio capaz de representar «al vivo la naturaleza del sujeto» (Huarte de San Juan, 1946: 63) construyó, legitimó e impuso una representación de mujer como sujeto incompleto dada su naturaleza fría y húmeda.

Los murmullos heterónomos de la práctica discursiva de María de Zayas y de Mariana de Carvajal se pueden considerar «excéntricos» en la medida que disienten del determinismo biológico y ofrecen resistencia a esas ideas imperantes. Ambas sujetos sociales, cada una a su modo, se sirven de la ficción para demostrar que el ingenio no debe ser considerado un atributo privativo del varón, y es por esto que en muchos de sus relatos el ingenio masculino es superado por el talento femenino. El ingenio zayesco conlleva el ejercicio de la invención, en donde la imaginación es la potencia creadora, y ambas, imaginación e invención, producen prácticas «como se ve en las respuestas de repente y en los engaños de pensado, que todo lo que se hace con maña, aunque no sea virtud, es ingenio» (Zayas, 2010: 160).

\section{OBRAS CITADAS}

Angenot, Marc (2010), Interdiscursividades. De hegemonías y disidencias, Argentina, Universidad Nacional de Córdoba.

Berriot-Salvadore, Evelyne (1993), «El discurso de la medicina y de la ciencia», en George Duby y Michelle Perrot (eds.), Historia de las mujeres. Del Renacimiento a la Edad Moderna. Discursos y disidencias, Madrid, Taurus, pp. 109-150.

Butler, Judith (2002), Cuerpos que importan. Sobre los límites materiales y discursivos del «sexo», Buenos Aires, Paidós.

Carvajal, Mariana de (1993) [1663], Navidades de Madrid, Madrid, Consejería de Educación y Cultura, Clásicos madrileños.

Covarrubias Orozco, Sebastián de (1995) [1611], Tesoro de la Lengua castellana o española, ed. Felipe Maldonado, Madrid, Castalia.

Cubillo Paniagua, Ruth (2002), Usos amorosos y conductas modélicas femeninas en el siglo XVII: una lectura de «Las navidades de Madrid y noches entretenidas» de Mariana de Carvajal, Tesis doctoral, Universidad de Barcelona, <www.tdx.cat/handle/10803/4865>.

De Lauretis, Teresa (2000), «Sujetos excéntricos», Diferencias. Etapas de un camino a través del feminismo, Madrid, Horas y horas, pp. 111-152.

Foucault, Michel (1991), Las redes del poder, Buenos Aires, Almagesto.

García Fanlo, Luis (2011), «¿Qué es un dispositivo?: Foucault, Deleuze, Agamben», Revista A Parte Rei. Revista de Filosofía, 74, <http://www.seminariofoucault.ecaths.com/>. 
Ingenio y mujer en el discurso hegemónico y heterónomo de la temprana modernidad española

García-García, Emilio (2003), «Huarte de San Juan. Un adelantado a la teoría modular de la mente», Revista de Historia de la Psicología, XXIV, 1, pp. 9-25.

Grossberg, Lawrence (2011), «Identidad y estudios culturales: ¿no hay nada más que eso?», en Stuart Hall y Paul du Gay (comps.), Cuestiones de Identidad Cultural, Buenos Aires, Amorrortu editores, pp. 148-180.

Hall, Stuart (2011), «Introducción: ¿Quién necesita "identidad”?», en Stuart Hall y Paul du Gay (comps.), Cuestiones de Identidad Cultural, Buenos Aires, Amorrortu editores, pp.13-39.

Huarte de San Juan, Juan (1946) [1575/94], Examen de ingenios para las ciencias, Buenos Aires, Espasa-Calpe.

Huarte de San Juan, Juan (2005) [1575/94], Examen de ingenios para las ciencias, ed. Guillermo Serés, Madrid, Cátedra.

Laqueur, Thomas (1994), La construcción del sexo. Cuerpo y género desde los griegos hasta Freud, Universidad de Valencia, Cátedra.

Lerner, Gerda (1990), La creación del patriarcado, Barcelona, Crítica.

Sánchez Dueñas, Blas (2008), De la invisibilidad a la creación, Sevilla, Renacimiento.

Zayas y Sotomayor, María de (2010) [1637], Novelas amorosas y ejemplares, ed. Julián Olivares, Madrid, Cátedra. 